\title{
A Complex Garment Assembly Line Balancing Using Simulation-based Optimization
}

\author{
OCIDENT BONGOMIN ${ }^{1}$, Josphat Igadwa $^{1}$, Eric Nganyi ${ }^{1}$, and Ildephonse Nibikora ${ }^{2}$ \\ ${ }^{1}$ Moi University \\ ${ }^{2}$ Busitema University
}

April 28, 2020

\begin{abstract}
The nascent wave of disruptive competition in the current business environment brought about by the fourth industrial revolution (Fashion 4.0 or Apparel 4.0) is enormous. Therefore, it is paramount important to apparel industry to be flexible enough to respond quickly to the unstable customers' demand through continuous improvement of their process efficiency and productivity. This study aims at achieving an optimal trouser assembly line balancing using simulation-based optimization via design of experiment. The empirical study is conducted at Southern Range Nyanza Limited (NYTIL) garment facility and a complex trouser assembly line with 72 operations is considered. The discrete event simulation of the trouser assembly line is developed using Arena simulation software. The local optimal solution is obtained from simulation experimentation and is adopted for the optimization process. The OptQuest tool is utilized to solve a single objective function (throughput) optimization problem. The results show that average throughput increases from the existing design (490 pieces per day) to local optimal design (638) and global optimal design (762). Consequently, the line efficiency increases from $61.2 \%$ to $79.7 \%$ to $95.2 \%$ respectively. The high increase in line efficiency and average throughput confirms the suitability assembly line balancing using simulation-based optimization via design of experiment.
\end{abstract}

\section{Hosted file}

ENGR_Manuscript final 3.docx available at https://authorea.com/users/316009/articles/446235a-complex-garment-assembly-line-balancing-using-simulation-based-optimization 